\title{
Colonização e educação no/do campo: conflitos e possibilidades na Amazônia Mato-Grossense
}

\author{
Leonir Amantino Boff \\ Isaura Isabel Conte \\ Universidade do Estado de Mato Grosso
}

\section{Resumo}

O texto apresenta uma breve retomada do processo de colonização na Amazônia Mato-grossense, enfatizando aspectos relacionados à floresta, aos povos indígenas nativos e às populações removidas, diante de uma perspectiva de desenvolvimento e de educação para o campo. Aborda-se, desse modo, a chamada modernização da agricultura, sob a lógica de mercado, aparecendo conflitos entre o agronegócio e a agricultura familiar e camponesa. Por fim, são lançados desafios em relação à sobrevivência e existência dos povos do campo e da floresta, implicando na agroecologia. Assim, compreende-se a necessidade de outro paradigma de desenvolvimento da sociedade e de conhecimento filosóficocientífico-tecnológico.

Palavras-chave: Colonização; Desenvolvimento; Educação; Amazônia MatoGrossense; Política de Agroecologia. 


\section{Colonization and education in/of the field: conflicts and possibilities in amazon mato-grossense}

This text is a short return of the colonization process in Amazon Mato-Grossense, emphasizing aspects related to the rainforest, indigenous people and removed populations, facing some perspective of development and education for the field. It approaches, this way, the so called, agriculture modernization, under the market logic, appearing conflicts between agribusiness against familiar and peasant agriculture. Finally, challenges are set in relation to surviving and existence of the people from the field and rainforest, implying agro ecology. Therefore, it is understood the necessity of other paradigm of development in society, as well some philosophic-scientific-technological knowledge.

Keywords: colonization; development; education; Amazon Mato-Grossense; agro ecology politics.

\section{Colonización y educación en lo/del campo: conflictos y posibilidades en la Amazonía en el Estado de Mato-Grosso}

Este artículo presenta una breve reanudación del proceso de colonización en Amazonía Mato Grosso/Brasil, haciendo hincapié en los aspectos relacionados con los bosques, los pueblos y las poblaciones indígenas nativas y las poblaciones desplazadas, ante una perspectiva de desarrollo y la educación para el campo. Se acerca así la nombrada modernización de la agricultura, bajo la lógica del mercado, aparecendo conflictos entre lo agronegócio y la agricultura familiar y campesina. Por último, lanzamos retos a la supervivencia y existencia de la gente de campo y el bosque, con implicaciones en la agroecología. Por lo tanto, entendemos la necesidad de otro modelo de desarrollo para el conocimiento social y filosóficocientífico-tecnológico.

Palabras-clave: la colonización; el desarrollo; la educación; La Amazonía Mato-Grossense; la política del agroecologia. 


\section{Introdução}

Por meio deste texto ${ }^{1}$, apresentamos algumas reflexões acerca do chamado desenvolvimento, abrangendo a questão educacional dos povos e populações da Amazônia Mato-Grossense, as políticas de "ocupação" e desterritorialização, os conflitos entre a agricultura familiar e camponesa com relação ao agronegócio e, também, recentemente, incluindo políticas para a agroecologia. Metodologicamente, baseamo-nos em estudos teóricos sem desconsiderar nossa participação em espaços críticos de reflexão acerca das temáticas, como em escolas do campo na região em questão e no comitê estadual de Educação do Campo do Estado de Mato Grosso.

Para a realização de um exercício compreensivo a respeito de possíveis conexões entre política educacional e política agroecológica, a qual é recente em nosso país, em vista de outro modelo de desenvolvimento do meio rural na Amazônia Matogrossense, partimos de uma visão em que consideramos a existência relacional, de complementariedade, correspondências e antagonismos da política com a ética e sem serem redutíveis uma à outra, elas estão numa relação de inseparabilidade. Por isso, sem separá-las e nem confundi-las ou reduzi-las uma à outra, é preciso compreendê-las numa relação em que "as grandes finalidades éticas exigem, com frequência, uma estratégia, ou seja, uma política, e a política exige um mínimo de meios e de finalidades éticas, sem por isso se reduzir à ética" (Morin, 2007, p. 80).

Ao trazermos o tema em discussão, a relação da política com a ética, remete-nos a pensar e reavaliar os processos de colonização e desenvolvimento implementado no meio rural no Estado de Mato Grosso de forma geral, e de modo mais específico na floresta Amazônica Mato-grossense, região norte do estado, colocada como exercício reflexivo neste trabalho. Isso porque há sinais bastante evidentes de que esse é um momento histórico de tomada de decisões importantes a respeito do que pretendemos em relação às possibilidades presentes e futuras quanto ao que se deseja manter e construir como condições básicas necessárias para as populações e povos permanecerem nessa região por tempos mais prolongados.

O modelo de desenvolvimento orientado pela voracidade econômica, com fortes impactos sobre a natureza e a sociedade, implementado como política de Estado a partir da década de 1960, balizado pela economia verde, segundo Dupas (2006), dão evidências, mesmo aos que não querem ver, que esse modelo, quanto aos seus fundamentos, está entrando em esgotamento ou em colapso, podendo nos deixar em condições profundamente fragilizadas.

\footnotetext{
${ }^{1}$ Parte da discussão deste texto foi apresentada no evento II SIFEDOC- II Seminário Internacional de Educação do Campo e Fórum Regional do Centro e Sul do RS, ocorrido no município de Santa Maria (RS) de 08 a 10 de outubro de 2014.
} 


\section{Impactos de colonização na Amazônia Mato-Grossense}

Compreendemos que, desde o processo de colonização, a ação na e sobre a região Amazônica Mato-grossense foi antrópica e desigual, orientada por relações de exploração e rapinagem desmedidas sobre a natureza, o uso descartável das pessoas, sejam povos indígenas originários, sejam trabalhadores (as) pobres. Ao mesmo tempo, esse lugar constituiu-se em oportunidades assombrosas para o enriquecimento de uma elite econômica e gerencial, que congregou e congrega empresas imobiliárias, instituições financeiras, empresas mineradoras, madeireiras e grandes empresas do agronegócio (Souza, 2004; Ribeiro, 2001; Oliveira, 1997) que estrategicamente se instalaram em lugares com riquezas naturais abundantes e se movimentaram e se movimentam quando a escassez e esgotamento dessas riquezas começa a ser vislumbrada.

Parece não haver mais dúvidas, embora ainda não seja tão amplamente conhecido pela sociedade brasileira, tampouco abertamente divulgado, de que os projetos de colonização na Amazônia Mato-grossense, que compôs a lógica política e econômica de integração nacional do regime militar pós 1964, caracterizou-se por um total desrespeito à biodiversidade, à diversidade étnica presente nessa região e pelo desrespeito quase absoluto às populações e povos que participaram desse processo ou foram afetadas por ele.

Nada deteve a volúpia por terras e riquezas vinda da parte das grandes empresas colonizadoras, seguidas pelas empresas mineradoras ávidas pela abundância de minérios existentes, pelas madeireiras, mutiladoras de corpos humanos (Souza, 2001), enlouquecidas diante da abundância de florestas ricas em diversidade de madeira. Além disso, pecuaristas que viam a oportunidade de se apropriar de quantidades abusivas de áreas de terra para expandirem seus rebanhos. À população empobrecida, restava a crença ilusória de que também seria bem sucedida e poderia compartilhar da riqueza existente e produzida, e construir alguma condição de vida melhor nesse lugar.

É importante compreendermos que o modelo de colonização privado fez com que ocorressem verdadeiros monopólios de terra principalmente na região norte de Mato Grosso, por parte de empresas imobiliárias e famílias alinhadas aos governos militares. Como analisa Oliveira (1997, p. 148; 170), "o interesse e a lógica do monopólio privado impôs-se antes de tudo. É por isso que cada parte daquela imensa região tem 'dono'. Sinop é do Enio Pipino², Alta Floresta do Ariosto da Riva, Matupá dos Ometto, Juara do Zé Paraná, etc". É absurdo, mas intrinsecamente lógico ao modelo de colonização, de que empresas como a Cotriguaçu tenha recebido 400 mil hectares de terra, a Juruena de João Carlos Meirelles 400 mil hectares, a

\footnotetext{
2 Sinop, nome da Cidade e do Município, é a sigla da colonizadora, e significa Sociedade Imobiliária Noroeste do Paraná, que colonizou esse lugar, e que também impôs o nome ao Município e à Cidade.
} 
INDECO de Ariosto da Riva 200 mil hectares, entre outras.

Essas grandes áreas de terras concedidas pelos governos militares às empresas e famílias influentes, muitas delas "mantiveram esses latifúndios como reserva de valor, fazendo especulação fundiária, até o final da década de 1970, quando Mato Grosso passou a receber um intenso fluxo migratório, aumentando com isso as demandas por terras" (Souza, 2004, p. 13).

Ainda no final da década de 1970 e início de 1980 realizaram-se algumas colonizações por meio de cooperativas. Temos com exemplos os casos da colonização de Terra Nova do Norte, realizada pela Cooperativa Mista Canarana - COOPERCANA (Schwantes, 1989), e dos municípios de Guarantã do Norte e Novo Mundo, pela Cooperativa Tritícola de Erechim - Ltda - COTREL. Em seguida, o INCRA também assentou, nessa região, famílias brasiguaias que perderam suas terras no Paraguai e famílias sem terra do Mato Grosso do Sul e Mato Grosso (Magalhães, 2010).

Esses processos de colonização foram apresentados com uma roupagem de política social, embora tenham servido para esvaziar os conflitos e as mobilizações pela democratização da terra nas regiões de onde as famílias eram originárias. Não por acaso, foram abandonadas à própria sorte em plena floresta Amazônica, totalmente desconhecida pelas famílias ao que concerne às caracterizações do bioma e às exigências de manejos para o cultivo nesse novo lugar, bem como de doenças, a exemplo da malária (Boff, 2014).

Muitas famílias assentadas, devido as constantes epidemias de malária, abandonaram suas terras e voltaram para sua região de origem. Outras tantas, inclusive as que foram chegando e compravam as terras dos que iam embora, também serviram como mão de obra para abertura das matas e formação de pastagens para as grandes fazendas na região, inclusive na divisa de Mato Grosso com o Pará, ou se aventuraram nos garimpos de ouro e diamante.

O primeiro impacto resultante da apropriação voraz dessas grandes áreas de terra ocorreu sobre as diversas etnias indígenas existentes. Na atualidade, há rumores orais na região a respeito de confrontos entre indígenas e exército durante a abertura da BR 163, que liga Cuiabá a Santarém, em que etnias indígenas foram dizimadas (Boff, 2014). Na mesma perspectiva, Oliveira (1997, p. 164-165) comenta a respeito do "contato destruidor dos trabalhadores que construíram Cuiabá-Santarém no norte do Estado, com os povos 'gigantes' Panará (também denominados Kreen Akarore) entre tantos outros". Tudo isso, sob um silenciamento típico desse processo, sendo os grupos indígenas remanescentes aldeados no parque Nacional do Xingu.

Junto com a morte dos povos indígenas também foram desenvolvidos processos de morte de suas culturas e de descaracterização de seus hábitos, sobretudo alimentares, na medida em que as intervenções de governos ofereciam cestas básicas compostas por alimentos de não índios, como forma de compensar o roubo de suas 
terras e das condições de seu habitat. Além disso, seus saberes foram totalmente desconsiderados em relação à proteção e tratamentos de doenças endêmicas como a malária, por exemplo, os saberes a respeito da floresta e a diversidade ali existente e, principalmente, nos modos de cultivar e conviver com a floresta. Ao projeto de desenvolvimento agroexportador do capital proposto para o Brasil, pós 1964 (Neto, 1997) e também para a Amazônia Mato-grossense, os indígenas representaram e ainda representam apenas um estorvo.

O segundo impacto importante foi relativo à destruição da floresta, num primeiro momento pela ação associada das madeireiras que extraíam apenas as espécies mais nobres, como a cerejeira, peroba, cambará e, de forma ilegal, a castanheira, entre outras, e das grandes derrubadas em sequência realizadas pela pecuária extensiva. No processo inicial da ação madeireira, o fato de algumas madeiras nobres serem bastante duras e dificultarem o seu beneficiamento, como a garapeira e o jatobá, por exemplo, era o suficiente para serem descartadas e destinadas ao fogo pósderrubada, quando formadas as áreas de pastagens.

Mais intensa que a ação dos madeireiros sobre a floresta foi à ação, na sequência, do desenvolvimento da pecuária extensiva. Essa era feita à base da "quebradeira" e do fogo, e em grande parte pelo trabalho escravo (Sato; Werner e Rossi, 2013). As chamadas "quebradeiras" eram uma estratégia para baratear os custos de roçada e derrubada da floresta, em que se roçava e derrubava apenas parte da vegetação e árvores e, como no período de estiagem a vegetação ficava muito seca, o fogo conseguia fazer suficientemente a destruição da área para semear ou plantar as pastagens.

Também na região colonizada por cooperativas, a ação das famílias sobre a natureza, mesmo sendo elas, de modo geral, originárias da agricultura familiar, também foi antrópica e a falta de orientação e suporte tecnológico com enfoque agroecológico e agroflorestal fez com que a utilização indiscriminada do fogo, permitida e incentivada nesse período, devastasse significativa parte das florestas. Muitas delas, em períodos de estiagem, queimaram de pé. Há um depoimento significativo do colonizador de Terra Nova do Norte sobre a voracidade do fogo durante as primeiras queimadas em plena Floresta Amazônica, na prática dos agricultores prepararem o terreno para as primeiras plantações:

Pouco antes das primeiras chuvas, no fim de agosto, combinamos o dia da grande queimada. Avisamos a todos que aguardassem, cada um na testada de seu lote, o sinal do sobrevoo do avião. No momento em que o avião passasse baixinho, poderiam atear fogo. Eu queria filmar esta enorme queimada, mas, no retorno do voo ficou difícil por causa da fumaça. Pousamos com dificuldade no leito da estrada diante do acampamento que servia de pista de pouso. A fumaça começou a tapar tudo. As labaredas atingiam 30 metros de altura, porque chegavam a queimar as copas das castanheiras que não haviam sido derrubadas. Desisti de fazer tomadas aéreas daquele inferno. Filmei a fogueira com os pés no chão. Era aterrorizadora a violência do fogo na selva (Schwantes, 1989, p. 182). 
Como não havia nenhuma outra orientação, a não ser aquela de roçar, derrubar e atear fogo na floresta, para que os agricultores pudessem experimentar outras formas de cultivo e atividades, por exemplo, a agroflorestal, em cada período de preparação das roças, o "inferno" das queimadas se repetia, destruindo a cada ano, outras tantas partes da floresta ainda em pé. Isso porque, após realizar a colheita, a forma de preparar o terreno para o novo plantio era, novamente, a roçada e o fogo, denominada "juquira" pelos agricultores da região. Com isso, as florestas próximas eram atingidas terrivelmente pelo uso do fogo indiscriminado e, ao mesmo tempo, necessário para as famílias desenvolverem suas roças.

Muitas das primeiras famílias que chegaram à região Amazônica mato-grossense, pouco tempo depois, abandonaram sua terra devido às constantes epidemias de malária (Boff, 2014). Ao mesmo tempo, havia outras tantas famílias de diversas regiões do Brasil querendo aventurar-se nessas terras, quase sempre iludidas por propagandas pouco honestas das colonizadoras. Quando se instalavam no novo lugar, acabavam por repetir as mesmas práticas de sobrevivência dos primeiros colonos assentados, desenvolvendo o cultivo de culturas de sua região de origem. É a partir dessa percepção que Boff e Souza (2013, p, 1444), afirmam que

[...] a existência da população migrante na região sempre foi antrópica. Os trabalhadores foram formados no trabalho em oposição à floresta, obrigados a vencê-la enquanto selva para plantar e arrancar mercadorias dos roçados, mal se mantiveram vivos. Várias foram as estratégias criadas para extrair de suas entranhas produtos in natura e transformálos em mercadorias, mal reproduziram suas vidas. Em razão das crises ambientais, são convocados a preservar a biodiversidade, em grande parte ainda desconhecida. Ao mesmo tempo, são desafiados a desenvolver outro modelo de agricultura em que a ecologia seja sua base de orientação prática.

Ao mesmo tempo, a educação nesse período, destinada à população migrante, foi primeiramente caracterizada pela dicotomia campo e cidade, visto que para as populações residentes no meio rural era destinada a "escolinha" dos quatro anos iniciais de escolarização. Esse modelo de escola pouco ajudou no sentido de orientar para a organização da vida nesse novo lugar, a não ser ensinar a ler, escrever e realizar as operações matemáticas básicas. Tamanho era o descaso do Estado que os prédios escolares existentes nas comunidades rurais quase sempre eram construídos de forma rústica pelas próprias famílias das comunidades. A escola mais completa era destinada aos núcleos de urbanização (Boff, 2014).

Contudo, as escolas existentes no meio urbano e as escolas técnico-agrícolas orientavam-se pela perspectiva tecnicista e difusora das novas tecnologias e conhecimentos, muitos deles importados nas formas de pacotes técnico-científicos, e também produzidos pelas instituições públicas de pesquisa, como universidades, EMBRAPA, entre outras. Também serviam como suporte para a divulgação de insumos importantes para a chamada "modernização da agricultura" (Neto, 1997, 
p. 81). Esse aporte de saber científico e tecnológico, tratado apenas na forma de repasse por aquele modelo de escolas, tem sua base de sustentação na lógica do "esclarecimento" moderno, que Adorno e Horkheimer (1985, p, 18) definem como um tipo de "saber que é poder" e que "não conhece barreira alguma". Ao mesmo tempo, longe de ser um tipo de saber desinteressado, está posicionado "a serviço de todos os fins da economia burguesa na fábrica e no campo de batalha, assim também está à disposição dos empresários, não importa sua origem".

Para os indígenas, segundo Stavenhagen (1988, p. 94), em 1973, o governo ditatorial do Brasil por meio da lei n. 6001/73 estabeleceu a instalação de uma escola em cada comunidade indígena e, no ano de 1979, vinculou a educação indígena ao Ministério da Educação, sendo essa destinada para "a adaptação de materiais". Essa orientação educacional indígena na Amazônia Mato-Grossense serviu muito mais para um processo de aculturação do que para um processo de reorganização de suas condições de vida, visto a forte imposição de um currículo externo às culturas indígenas. Somente a partir da segunda metade da década de 1990 é que começou um processo de experimentação de organização educacional a partir da concepção indígena, com desenvolvimento de Programas e Projetos educacionais e de formação de professores de nível médio e superior Indígena (Mato Grosso, 2010).

Do ponto de vista das atividades econômicas, até o fim do século XX, na Amazônia Mato-grossense alternaram-se e combinaram-se os ciclos da madeira, da pecuária extensiva e da mineração e, em alguns lugares, a agricultura familiar e camponesa. Quase todos combatendo a floresta, embora seja importante considerar que uma pequena parcela dessa população e alguns grupos econômicos, enriqueceram muito pela exploração da natureza e a grande maioria da população mal produzia suas subsistências, conseguindo sobreviver às doenças e ao descaso total por parte do Estado.

O terceiro grande impacto pode ser considerado a partir da primeira década do século XXI, quando a Amazônia Mato-grossense passou a ser cobiçada pelos grandes plantadores de soja e de milho. Muitas áreas foram adquiridas por grandes empresas do agronegócio, que já vinha se estabelecendo na região desde a década de $1990 \mathrm{com}$ amplo apoio do Estado por meio de recursos e infraestrutura (Guanziroli; Berenger, 2010). Além disso, parte das terras dos agricultores familiares em dificuldades estão sendo arrendadas em contratos firmados por tempo de uso entre 8 (oito) e 15 (quinze) anos. Os arrendatários são médios e grandes plantadores de soja, milho e algodão do bioma cerrado, que pretendem expandir suas áreas de plantio. Como no cerrado não há mais espaço para isso, buscam formas de conseguilo na região da Floresta Amazônica Mato-Grossense e Paraense. 


\section{Educação do campo e o agronegócio no contexto da Amazônia Mato-Grossense}

Com relação ao atendimento educacional no meio rural, durante a década de 1990, ao invés de uma política de melhoria das propostas educacionais, da infraestrutura escolar e do suporte tecnológico, didático e pedagógico, o que ocorreu foi o fechamento das "escolinhas" nas comunidades, e a implementação da política, denominada indústria do transporte escolar, sendo através da mesma as crianças transportadas do campo para as escolas na cidade (Boff, 2014).

$\mathrm{Na}$ primeira década do século $\mathrm{XXI}$, ao revés do modelo de desenvolvimento imposto, os movimentos sociais do campo, reagindo à volúpia do agronegócio e às políticas públicas estatais de fortalecimento a esse modelo, tencionaram para que as Diretrizes Operacionais da Educação Básica nas Escolas do Campo e as Licenciaturas da Educação do Campo fossem instituídas e, aos poucos, implementadas por meio de políticas públicas de governos e universidades. A partir disso, e desde as ações do PRONERA, temos uma ampliação da Educação do Campo com experiências diversas (Fernandes, 2008) de ensino superior, com cursos de licenciatura e bacharelados em diversas áreas do conhecimento, cursos técnicos de ensino médio na modalidade integrado à educação básica, muitos deles em agroecologia.

Também na década de 1990, tivemos uma reação importante à agressão produzida ao meio ambiente pelo modelo de desenvolvimento que deu origem à $\mathrm{ECO} / 92$, tendo tratado da importância da Ecologia, mas que não resistiu suficientemente aos interesses do mercado. Dupas (2006, p. 251) aponta em seus estudos "O mito do progresso", que a ECO/92 foi uma farsa sob a concepção de que poderia haver desenvolvimento sem destruição ambiental, conforme defende o acordo de Brundtland "nosso futuro comum", mas que, na realidade, põem a natureza ao sabor dos mercados. O autor afirma que, nessa conferência, em nome de cuidar do planeta, os empresários encontraram mais um nicho de mercado para lucrar com a natureza que ainda existe.

Na Amazônia Mato-Grossense, especificamente, o que percebemos é o avanço do modelo de agricultura que ocorreu sobre a região do cerrado a partir da década de 1970 com a chamada modernização da agricultura brasileira e que, na atualidade, impõe-se sobre a Floresta Amazônica. Esse processo se sustenta em políticas de "incentivos fiscais e financeiros para a promoção do aumento da produção, e investimentos à comercialização e à transformação tecnológica no setor agrícol a". O mesmo articula-se à "disseminação do uso de insumos modernos" e com programas de "pesquisa agrícola em grande dimensão" (Neto, 1997, p. 133), financiada publicamente pelo Estado Brasileiro, o que deu fundamentalmente as condições necessárias para o desenvolvimento do agronegócio brasileiro. Esse modelo foi implantado com toda força sobre cerrado mato-grossense, a tal ponto deste ter sido 
explorado praticamente em toda sua extensão e, agora, a mesma ação se desdobra sobre o bioma amazônico.

A ação sobre o restante da floresta e a natureza amazônica mato-grossense, de agora em diante, não será mais pela ação do fogo, mas pelas grandes máquinas computadorizadas, pelos equipamentos sofisticados e principalmente pelo uso abusivo de agrotóxicos e sementes transgênicas, como já são utilizados no bioma cerrado. Se pela ação do fogo a vegetação conseguia se reestabelecer mesmo com a morte de algumas espécies e a dificuldades de outras se recuperarem, com a ação das grandes máquinas e dos agrotóxicos pesticidas, ela será totalmente eliminada. No projeto moderno do "esclarecimento" (Adorno; Horkheimer, 1985, p. 18), o fim último do seu saber é o controle:

[...] O que os homens querem aprender da natureza é como empregá-la para dominar completamente a ela e aos homens [e mulheres]. Nada mais importa. Sem a menor consideração consigo mesmo, o esclarecimento eliminou com o seu cautério o último resto de sua própria autoconsciência.

Por isso, pouco importam as manifestações colaterais dolorosas decorrentes das ações de controle, como aparecem nos estudos publicados a respeito dos malefícios sobre a saúde humana e animal provocados pelo uso abusivo de agrotóxicos decorrentes das práticas agrícolas desenvolvidas pelo modelo tecnológico do agronegócio (Wolfart e Junges, 2014; Londres, 2011).

Para além de uma lógica de desenvolvimento concentrador de terras e de riquezas e de uma cultura do adoecimento, a entrada do agronegócio na região amazônica mato-grossense já, por assim dizer, significa maior esvaziamento das populações das comunidades do meio rural. Aliás, algumas escolas das comunidades rurais já vêm sentindo os primeiros impactos pela perda de estudantes, cujas famílias venderam ou arrendaram suas terras e deslocaram-se para agrupamentos urbanos (Boff, 2014). Nesse sentido, a estrutura do Estado está a favor do agronegócio, sendo um exemplo disso, a isenção de impostos dos seus produtos pela Lei Kandir, deixando o próprio Estado do Mato Grosso com bem menos recursos para investir em saúde e educação como política pública.

A decisão tomada pelos agricultores familiares de vender ou arrendar suas terras decorre fundamentalmente do desânimo frente às dificuldades de viabilizar economicamente e com segurança suas atividades agrícolas. As dificuldades, dessa forma, encontram sua razão na incompatibilidade entre a organização fundiária dos pequenos agricultores caracterizada por pequenas porções de terra e o modelo agrícola desenvolvido e caracterizado pelo incentivo fundamental, com aporte científico-tecnológico e de financiamento às atividades monoculturais, como criação de gado ou cultivo de milho, de arroz ou soja, que exigem, ao mesmo tempo, a intensificação da produção em grandes extensões de terra. As longas distâncias 
existentes devido à logística construída em favor do funcionamento dos latifúndios inviabilizam e deixam os camponeses isolados, dificultando ou inviabilizando o acesso à comercialização tanto de seus produtos quanto do que necessitam para a reprodução da vida com dignidade.

A própria pressão exercida pelo sistema atual do agronegócio, que ao longo dos tempos foi tomando terras com o aval ou juntamente com o sistema e aparato estatal e jurídico, amparando e legitimando inclusive grilagem de terra, sendo um dos principais motivos pela expulsão de famílias da pequena agricultura. Em tempos passados, havia a possibilidade de adentrar a mata, mas isso era permitido somente a quem tinha poder aquisitivo suficiente para manter-se na terra apropriada. De acordo com Martins (1995), os latifúndios foram constituídos por força e muitos jagunços a serviço dos patrões, que, por sua vez, foram legitimando a terra de exploração versus terra para quem nela precisa trabalhar para sobreviver, mas, no caso de grilagem, sempre se vivia em fuga.

Essas incompatibilidades exigem uma mudança fundamental do modelo agrícola a ser desenvolvido com as famílias camponesas para que não cedam mais às pressões feitas pelo capital agroindustrial que pretende se apropriar também das microrregiões organizadas pela pequena agricultura. Uma alternativa possível e viável do ponto de vista social, econômico e ecológico é o desenvolvimento de uma agricultura de base agroecológica, mas que só pode acontecer se houver uma ação política efetiva do Estado.

Primeiramente, o Estado deve garantir que as famílias camponesas, ou outras formas de organização coletiva, possam permanecer em suas parcelas de terra sem serem fustigadas constantemente pelo poder do agronegócio. A agroecologia, mais que alternativa, é uma necessidade urgente para a viabilidade da agricultura familiar camponesa, inclusive na região Amazônica, pois, por meio dela, é possível trabalhar e sobreviver com a mata, ou pelo menos com boa parte dela em manejo sustentável. O agronegócio, através de seus mecanismos ideológicos, divulga seus números exorbitantes na balança comercial, colocando o país como o maior exportador de matérias-primas, inclusive sendo o maior exportador de soja, com uma área de mais de 30 milhões de hectares de plantação transgênica (Guanziroli; Berenger, 2010) e, assim, divulga-se o sucesso do setor. De outro modo, porém, não considera as consequências catastróficas, como fazer do Brasil, desde o ano de 2008, o campeão em uso de agrotóxico, chegando a mais de 5 litros/pessoa ao ano e um terço dos alimentos consumidos no país estarem contaminados por agrotóxicos (Abrasco, 2012).

Diante disso, é urgente não maquiar a realidade em nome de interesses financeiros e comprometimento com as elites locais e transnacionais que fazem dos países "em desenvolvimento" o seu ramo de negócios ao custo do adoecimento, inviabilidade e morte das populações camponesas e indígenas de forma especial. Muito embora 
as populações de vilarejos e cidades também sejam diretamente afetadas com os agrotóxicos e com as políticas que desalojam os povos do campo, da floresta e das águas de suas localidades, as populações expulsas de campo são duplamente afetadas. Como contraponto, a agroecologia é uma orientação paradigmática, que implica sempre uma postura de abertura para a escuta e descoberta, para um posicionamento epistemológico técnico e práticas coerentes. Como afirma Altieri (2004, p, 23),

uma abordagem agroecológica incentiva os pesquisadores a penetrar no conhecimento e nas técnicas dos agricultores e a desenvolver agroecossistemas com uma dependência mínima de insumos agroquímicos e energéticos externos. O objetivo é trabalhar com e alimentar sistemas agrícolas complexos onde as interações ecológicas e sinergismos entre os componentes biológicos criem, eles próprios, a fertilidade do solo, a produtividade e a proteção das culturas [...].

Assim, defendemos ser necessário que essa visão tome forma a partir da Política Nacional de Agroecologia e Produção Orgânica, instituída pelo Decreto 7.794, de 20 de agosto de 2012, e do Plano Nacional de Agroecologia e Produção Orgânica 2013-2015. O Plano, por sua vez, precisa ser ampliado por pelo menos uma década e, como consequência, deixar de ser plano, para ser política de Estado. Por outro lado, esta mesma política deverá diminuir os investimentos em um sistema de agricultura dependente e destruidor, que por estar no centro das políticas agrícolas desenvolvidas no Brasil desde a década de 1960, com investimentos estatais imponentes, nos campos científico, técnico, infraestrutura logística, e financiamentos subsidiados, arroga para si a sustentação da balança comercial brasileira positiva.

Concomitantemente, além dos investimentos em pesquisa e produção de tecnologia em favor da agroecologia, a educação e a pesquisa podem cumprir um papel fundamental, como houvera cumprido em favor "do modelo convencional", que levou à situação em que nos encontramos nos dias atuais. Para evidenciar essa relação: educação com "modelo" de desenvolvimento, encontramos um pequeno fragmento do programa de ação econômica do governo 1964-1966, do Ministério do Planejamento e Coordenação Econômica, que afirma o seguinte:

Dentro dessa ordem de ideias, a estratégia para a modernização da agricultura há de repousar fortemente na educação. Educação no seu sentido mais genérico, que significa prover o habitante do quadro rural com um mínimo de escolaridade, elevar-lhe os padrões culturais pela via de extensionismo e transmitir-lhe uma tecnologia nova pela demonstração (Neto, 1997, p. 128).

Embora possa ser percebida uma série de equívocos pedagógicos e de concepção educacional naquele programa, e uma perspectiva preconceituosa frente ao "habitante do quadro rural", o mesmo nos põe em alerta no sentido de que sem um processo educacional, da Educação Básica ao Ensino Superior, fortemente 
orientado por aprendizagens pela pesquisa, produção de saberes e tecnologias agroecológicas, juntamente com financiamento para implementar práticas produtivas agroecológicas, a Política Nacional e Plano Nacional muito provavelmente cairão no vazio e no descrédito. Ao mesmo tempo, será preciso mudar a orientação educacional escolar pautada no modelo do "esclarecimento", pois, como salientam Adorno e Horkheimer (1985, p. 17), "Hoje, apenas presumimos dominar a natureza, mas, de fato, estamos submetidos à sua necessidade; se, contudo, nos deixássemos guiar por ela na invenção, nós a comandaríamos na prática".

A educação escolar que atenderá camponeses e camponesas nesse sentido terá que deixar de ser uma mera transferidora de conhecimento e pacotes tecnológicos, que atende os interesses de grupos dominadores, e passar a orientar-se para a formação de uma sensibilidade diferente, para outra perspectiva de relação com a natureza e desenvolvimento de saberes. O cuidado ontológico (Heidegger, 2009) e o cuidado ecológico (Boff, 2000), deverão ser os fundamentos dessa nova orientação educacional, articulados a uma epistemologia construída em bases paradigmáticas agroecológica (Altieri, 2004), complexa (Morin, 2008) e sustentável (Capra, 2002).

$\mathrm{Na}$ região amazônica mato-grossense há potenciais importantes para práticas agroecológicas produtivas, como, por exemplo, o cultivo da Castanha do Pará ou Castanha do Brasil, cultivo do pequi, do cupuaçu, do açaí, de uma variedade de espécies nativas potenciais que poderiam ser desenvolvidas como atividades agroflorestais. Mesmo que essas atividades circundem uma aproximação compreensiva do que seja a agroecologia, ainda necessita de um caminhar mais convicto num sentido que Sepúlveda (2005, p, 87) indica, a agroecologia como sendo "uma ciência fundamentada em princípios ecológicos", apresentando três aspectos básicos diferenciadores aos "métodos convencionais de produção",

a) Combina práticas tradicionais superiores com tecnologia e com técnicas modernas ad hoc, tendo por objetivo manejar exitosamente a biodiversidade;

b) É uma das práticas mais confiáveis nos processos de restauração de áreas degradadas, i.é., encostas, áreas de fragilidade ecológica, etc,;

c) Surge como alternativa de produção ecologicamente amigável e custos reduzidos, acessíveis à capacidade financeira dos pequenos produtores, permitindo-lhes intensificar sua produção até em áreas marginais.

No aspecto educacional, há experiências nascentes importantes de cursos técnicos em Agroecologia na modalidade médio integrado, em diversas escolas públicas estatais na região. Estas, se combinadas com a implementação disseminada de cursos superiores em Agroecologia, poderão constituir uma rede educativa filosófica/ científica/tecnológica importante para o desenvolvimento e aprofundamentos 
de aprendizagens em agroecologia. Na perspectiva de Costa (2006, p. 127), a agroecologia precisa ser compreendida como

[...] uma abordagem que integra os princípios agronômicos, ecológicos, socioeconômicos e político-institucionais à compreensão e avaliação do efeito das tecnologias sobre os sistemas agrícolas e a sociedade; que utiliza os agroecossistemas como unidade de estudo, ultrapassando a visão unidimensional genética, fisiológica, edafológica, etc., incluindo dimensões ecológicas, econômicas, sociais, políticas e culturais.

Concomitantemente ao desenvolvimento de uma política educacional de ciência e tecnologia em favor de uma agricultura agroecológica, será igualmente importante que o Estado Brasileiro, juntamente com o Estado de Mato Grosso, reavalie os mecanismos históricos praticados para a concessão de terras. A partir disso, devese instituir uma política séria de democratização da terra e de reforma agrária, sem a qual os agricultores camponeses continuarão em dificuldades de se estabelecerem em suas comunidades para desenvolver a agroecologia na região amazônica matogrossense.

\section{Referências}

ABRASCO. Dossiê ABRASCO: um alerta sobre os impactos dos agrotóxicos na saúde. Abrasco: Rio de Janeiro, 2012. (volume 1: Agrotóxicos, segurança alimentar e nutricional e saúde).

ADORNO, Theodor W. e HORKHEIMER, Max. Dialética do esclarecimento: fragmentos filosófico. Tradução, Guido Antônio de Almeida. - Rio de Janeiro: Zahar, 1985.

ALTIERI, Miguel. Agroecologia: a dinâmica produtiva da agricultura sustentável. 4. ed. Porto Alegre: Editora da UFRGS, 2004.

BOFF, Leonardo. Ethos mundial: um consenso mínimo entre os humanos. Brasília: Letraviva, 2000.

BOFF, Leonir Amantino. Educação do campo no portal da Amazônia: Entrelaçamentos Ético-Político-Estéticos. 2014. Tese (Doutorado) Universidade Federal do Rio Grande do Sul, Faculdade de Educação, Programa de Pós-Graduação em Educação, Porto Alegre, 2014. 
; SOUZA, Maria Ivonete de. Desigualdades, demografia, acceso a La tierra y educación rural en Amazonia "MATO-GORSSENSE"/Brasil. In: $2^{\circ}$ CONGRESO LATINOAMERICANO DE CIENCIAS SOCIALES "LAS CRISIS EN AMÉRICA LATINA, DIFERENTES PERSPECTIVAS Y POSIBLES SOLUCIONES", 2, 2013. Zacatecas, México. Anais. Zacatecas, México: Universidad Autónoma de Zacatecas, 2013. p. 1434-1449.

CAPRA, Fritjof. As conexões ocultas: ciência para uma vida sustentável. Tradução de Marcelo Brandão Cipolla. São Paulo: Cultrix, 2002.

COSTA, Gilson da Silva. Desenvolvimento rural sustentável com base no paradigma da agroecologia. Belém: UFPA/NAEA, 2006.

DUPAS, Gilberto. O mito do progresso. 2. Reimpressão. São Paulo: Unesp, 2006.

FERNANDES, Bernardo Mançano. Educação do Campo e Território Camponês no Brasil. In: FERNANDES, Bernardo Mançano et. al. Educação do Campo: campo políticas públicas - educação. Organizadora Clarice Aparecida dos Santos. Brasília: Incra; MDA, 2008.

GUANZIROLI, Carlos; Marco Ortega BERENGER. Experiências bem - sucedidas em agronegócio no Brasil e desenvolvimento sustentável. Brasília/DF: IICA, 2010.

HEIDEGGER, Martin. Ser e tempo. Tradução revisada e apresentação de Márcia Sá Cavalcante Schuback; prefácio de Emmanuel Carneiro Leão. 4. edição, Petrópolis: Vozes, 2009.

LONDRES, Flavia. Agrotóxicos no Brasil: um guia para ação em defesa da vida. Rio de Janeiro: AS-PTA - Assessoria e Serviços a Projetos em Agricultura Alternativa, 2011.

MAGALHÃES, Nancy Alessio. Memórias-terra, fazeres da vida. In: BARROZO, João Carlos (Org.). A Questão agrária em Mato Grosso: a persistência da grande propriedade. São Leopoldo: Oikos; Unisinos; Cuiabá/MT: EdUFMT, 2010. p. 65 105.

MARTINS, José de Souza. Os camponeses e a política no Brasil. As lutas sociais no campo e seu lugar no processo político. 5. ed. Petrópolis: Vozes, 1995.

MORIN, Edgar. O método 6: ética. Tradução Juremir Machado da Silva. 3 ed. Porto Alegre: Sulina, 2007.

O método 3: conhecimento do conhecimento. Tradução de Juremir Machado da Silva. 4. ed. Porto Alegre: Sulina, 2008. 
MATO GROSSO. Secretaria de Estado de Educação. Orientações Curriculares: Diversidades Educacionais./ Secretaria de Estado de Educação de Mato Grosso. Cuiabá: Defanti, 2010. 308p.

NETO, Wenceslau Gonçalves. Estado e agricultura no Brasil: política agrícola e modernização econômica brasileira 1960 - 1980. São Paulo: Hucitec, 1997.

OLIVEIRA, Ariovaldo Umbelino de. A Fronteira Amazônica Mato-Grossense: grilagem, corrupção e violência. Tese apresentada no Curso de Livre Docente na Faculdade Filosofia, Letras e Ciências Humanas da Universidade de São Paulo. São Paulo, 1997.

POLÍTICA NACIONAL DE AGROECOLOGIA E PRODUÇÃO ORGÂNICA. Decreto n. 7.794, de 20 de agosto de 2012.

RIBEIRO, J. Donizete. Terra e garimpos: um estudo da violência na consolidação do espaço de colonização. Alta Floresta - MT (1978 - 1983). 2001. Dissertação (Mestrado), Universidade Federal de Mato Grosso, 2001.

SATO, Michèle; WERNER, Inácio e ROSSI, Roberto (Orgs.). Relatório de direitos humanos e da terra 2013. Cuiabá: FDHT / Centro Burnier Fé e Justiça, 2013.

SCHWANTES, Norberto. Uma cruz em Terra Nova. São Paulo: Scritta, 1989.

SEPÚLVEDA, Sérgio. Desenvolvimento sustentável microrregional - Métodos para planejamento local. Brasília: IICA. 2005. 296 p.

SOUZA, Edison Antônio de. Sinop: História, imagens e relatos. Um estudo sobre a sua colonização. Cuiabá: Institutos de Ciências Humanas e Sociais, 2004.

SOUZA, Maria Ivonete de. Migração e rotatividade escolar na área madeireira de Sinop/MT. Dissertação de Mestrado. UFMT: 2001.

WOLFART, Graziela e JUNGES, Márcia. Não Existe uso seguro de Agrotóxicos. Revista do Instituto Humanitas unisinos - ON - Line. São Leopoldo - RS, n. 368, ano XI, 04.07.2011. Disponível em: WWW.ihuonline.unisinos.br/index. php?option=com_content=article\&id=3975\&secao 368 acesso em: 03 jan. 2014. 
Recebido em maio de 2015

Aprovado em outubro de 2015

Leonir Amantino Boff é doutor em Educação pela Universidade Federal do Rio Grande do Sul (UFRGS) e professor da Universidade do Estado de Mato Grosso (UNEMAT), Campus Universitário de Sinop, MT. E-mail: leonirboff@gmail.com

Isaura Isabel Conte é doutora em Educação pela Universidade Federal do Rio Grande do Sul (UFRGS) e professora da Universidade do Estado de Mato Grosso (UNEMAT), Campus Universitário de Cáceres, MT. E-mail: isauraconte@yahoo.com.br 